\section{Turkey's scientists can't ignore politics}

Given the severity of the political problems that scientists face in Turkey, academics need to become more politically involved - not less, as you suggest - to help bring about reform to the country's academic system (see Nature 500, 253; 2013).

There is no clear evidence to support your implication that the debate over the headscarf ban in Turkish universities has affected the quality of their scientific research. Other long-standing impediments are the real culprits.

Scientists in Turkey have had to contend for years with a lack of academic freedom and transparency in grant-review and faculty-recruitment processes. The small size of the academic community and a clumsy bureaucracy further obstruct the nation's research potential.

There are some notable successes, however. Contrary to your description of Boğaziçi University as "cash-starved", in 2010 researchers there gained funding of close to US $\$ 13$ million, of which more than $\$ 2$ million came from highly competitive international sources (see go.nature.com/wik8xn). Ozan Aygün Massachusetts Institute of Technology, Cambridge, USA. oaygun@mit.edu

\section{Transcranial devices are not playthings}

Controlled investigation of transcranial direct-current stimulation (tDCS) for treating neuropsychiatric disorders or for neurorehabilitation should not be confused with improvised devices or practices that apply electricity to the brain without reference to established protocols (see Nature 498, 271-272; 2013). Unorthodox technologies and applications must not be allowed to distort the long-term validation of tDCS.

Experimentation outside established and tested norms may put subjects at risk. In tDCS, the delivered dose of electrical brain stimulation (defined by the waveform and intensity applied) and the electrode size, number and position are all crucial. Safe and effective dose ranges have been established in clinical trials. Patients receiving $\mathrm{tDCS}$ do so in a controlled environment, under guidance from institutional ethics review boards and with strict criteria for patient inclusion.

Meddling with the tDCS dose is potentially as dangerous as tampering with a drug's chemical composition. Painstaking efforts by researchers to understand the risks and benefits of tDCS should never be interpreted as encouraging such practices. Marom Bikson City College of New York, USA.

bikson@ccny.cuny.edu

Sven Bestmann University

College London, UK.

Dylan Edwards Burke-Cornell

Medical Research Institute, New York, USA.

M. B. declares competing financial interests: see go.nature.com/lxuxfq for details.

\section{Don't compromise on informed consent}

I urge researchers responding to the call for information about sharing data sets (M. Bobrow Nature 500, 123; 2013) to defend the important principle of informed consent by patients participating in medical research.

The UK Health and Social Care Act 2012 requires the transfer of all National Health Service electronic medical records in England from general practitioners to the Health and Social Care Information Centre. The biomedical research charity the Wellcome Trust and the Human Genomics Strategy Group have proposed that variant files, which contain whole human genomes minus the Sanger Institute reference genome, should be attached to the records.

The UK government's intention is to share these data with accredited researchers - ranging from the Googlefunded gene-testing company 23 andMe to private health-care companies and Chinese research institutes - but without people's knowledge or consent.

Most data will be 'pseudoanonymized', with some identifiers (such as names) stripped out, but with the ability to link back to the individual retained. People can opt out of this data-sharing system (see go.nature.com/azkyru), but that will in effect prevent members of the public from taking part in medical research.

Abandoning informed consent is unlikely to benefit biomedical research (J. P. A. Ioannidis Am. J. Bioethics 13, 40-42; 2013). Researchers could face a dwindling source of data as people withdraw from participation to protect their confidentiality.

Helen Wallace GeneWatch UK, Buxton, UK.

helen.wallace@genewatch.org

\section{HeLa genome versus donor's genome}

I contend that the continual divergence of chromosomal features ('karyotype') and DNA sequence in dynamic cancercell populations undermines debate over ownership of the HeLa cancer-cell line derived from Henrietta Lacks six decades ago (see Nature 500, 121 and 132-133; 2013).

The HeLa genome is no longer Henrietta Lacks's personal genome. Although the two share some DNA sequences, the similarity ends there. Lacks's genome had the usual number of 46 normal chromosomes, whereas most HeLa cells have 70-90 chromosomes and more than 20 translocations, some of which are highly complex.

Changes in the HeLa genome in the past few decades have resulted from multiple cycles of genome reorganization during the cancer process and from the initial cell-culture experiments. Considering that chromosomes provide the genome identity and blueprint, it might even be argued that the HeLa genome is no longer a human genome. Henry H. Heng Wayne State University School of Medicine, Detroit, USA.

hheng@med.wayne.edu

\section{A forgotten history of sex research}

Elizabeth Pollitzer's point about sex mattering in all areas of biology has long been considered an important topic (see Nature 500, 23-24; 2013).

For example, the Endocrine Society's flagship journal Endocrinology, of which I am editor-in-chief, has since 2012 required authors to include the sex of animals, tissues and even cell lines in their papers (J. D. Blaustein Endocrinology 153, 2539-2540; 2012). Authors must justify the use of single-sex animals or tissues, and consider sex in interpreting their data.

Research in neurobiology and psychology has also consistently recognized sex differences in physiology, pathophysiology, pharmacology and toxicology (see, for example, G. E. Gillies \& S. McArthur Pharmacol. Rev. 62, 155-198; 2010). The US National Institutes of Health supports such research and has emphasized its importance in programme announcements.

From 1922, the US Committee for Research in Problems of Sex was funded by the Rockefeller Foundation for decades. In 2006, the Organization for the Study of Sex Differences, based in Atlanta, Georgia, was founded for researchers and clinicians.

Studies on sex differences published before the PubMed online archive, electronic journals and searchable keywords should not be overlooked. Andrea C. Gore University of Texas at Austin, USA. andrea.gore@austin.utexas.edu 